\title{
Saneamento básico: um estudo na Região Metropolitana da Grande São Luís
}

\author{
Basic sanitation: a study in the Região Metropolitana da Grande São Luís
}

\author{
Débora Danna Soares da Silva '
}

\section{RESUMO}

A falta de acesso universal ao saneamento básico acaba comprometendo a saúde pública da comunidade, assim o serviço de saneamento básico eficiente tem grande poder e deve fazer parte de políticas públicas prioritárias. Com isso, este trabalho teve como objetivo diagnosticar os serviços de saneamento básico da Região Metropolitana da Grande São Luís, através da percepção do usuário. A metodologia utilizada foi a aplicação de questionários, os quais foram tratados através de método estatístico, sendo aplicados em 117 residências nos meses de abril e maio de 2019. De acordo com os resultados, verificou-se que o serviço de saneamento mais deficiente em toda Região Metropolitana é o esgotamento sanitário, percebeu-se que os índices de atendimento são baixos e tem municípios da Região Metropolitana que não possui qualquer atendimento referente a esse serviço. Além disso, conforme usuários, os serviços de limpeza urbana e manejo dos resíduos sólidos são os melhores consolidados. Assim, conclui-se que a metodologia de avaliação do sistema a partir da percepção do usuário mostrou-se ferramenta importante para a gestão, para o planejamento, para a credibilidade do sistema e para monitorar a prestação dos serviços.

Palavras-chave: Levantamento; Qualidade ambiental; Infraestrutura; Monitoramento; Usuário.

\begin{abstract}
Population growth, urbanization, economic and technological development have led to changes in lifestyle, changing modes of production and consumption. Thus, they resulted in an increase in both quantity and diversity of solid waste generation. Consequently, there is a need to promote an adequate final disposition of the waste generated. The present study aimed to propose improvements for the management of organic solid waste from a Higher Education Institution, when four areas of organic waste disposal were delineated and quantified in the study area. As a result, it is possible to highlight the place where the university restaurant operates, which presented the highest percentage of organic waste, $84 \%$ of the total $(142,240 \mathrm{~g})$. It was verified that there is not a correct destination of the organic residues generated. Composting is a viable way for environmentally appropriate disposal, using waste in urban and rural agriculture as fertilizer. It is important to highlight that the simple implementation of a composting system does not solve the serious problems of the incorrect destination, which pollutes and presents environmental risk. Thus, it was necessary to prepare and present a Management Plan for Organic Solid Waste for the Institution under study, aiming to propose environmentally appropriate planning and management.
\end{abstract}

Keywords: Lifting; Environmental quality; linfrastructure; Monitoring; User.

'Mestranda em Tecnologia e Gestão Ambiental, IFCE. E-mail: dannasilva94@gmail.com. ORCID: https://orcid.org/0000-0002-8239-655X. 


\section{INTRODUÇÃO}

Segundo a Lei Federal $n^{\circ} 11.445 / 2007$ que estabelece as diretrizes nacionais para o saneamento básico, "os serviços de saneamento básico compreendem o abastecimento de água potável; esgotamento sanitário; limpeza urbana e manejo de resíduos sólidos; e drenagem e manejo das águas pluviais" (BRASIL, 2007, art. 30, p. 2). A deficiência na prestação de tais serviços tem impacto direto na qualidade de vida da sociedade.

No Brasil o acesso ao saneamento básico ainda não é universal, conforme dados divulgados pelo Plano Nacional de Saneamento Básico (PNSB) 6,8\% da população urbana brasileira ainda não têm acesso à água potável, 9,6\% da população não é atendida por rede de esgotamento sanitário e $14,2 \%$ não possui acesso aos serviços de limpeza urbana e manejo de resíduos sólidos (BRASIL, 2013). De maneira generalizada a falta de todos esses serviços representa milhões de pessoas vivendo em ambientes insalubres e expostos a diversos riscos que podem comprometer a sua saúde.

Como mencionado, a falta de acesso universal ao saneamento básico acaba comprometendo a saúde pública da comunidade, posto que diante da carência de investimentos na área, a população fica exposta aos malefícios da disposição ambientalmente irregular de resíduos sólidos e esgoto lançado a céu aberto, fatores que contribuem diretamente para proliferação de vetores de doenças; e comprometem o bemestar físico e mental da população, além de comprometer os recursos hídricos (ARAÚJO et al., 2016).

Logo, o serviço de saneamento básico eficiente tem grande poder e deve fazer parte de políticas públicas prioritárias. Neste sentido, uma das ferramentas para demonstrar a capacidade de um sistema para que venha a subsidiar os gestores na tomada de decisões voltadas à melhoria contínua e sustentável do mesmo é a avaliação a partir da percepção do usuário (GONÇALVES, FERNANDES e GIRARD, 2015).

No entanto, estudos que investigam aspectos sociais para analisar a aceitação pública e as suas preocupações ainda são escassos (MAINALI et al, 2013), bem como levantamento da situação do saneamento na Região Metropolitana da Grande São Luís. 
Sendo assim, este trabalho visa caracterizar a prestação dos serviços de saneamento básico na Região Metropolitana da Grande São Luís a partir da percepção do usuário.

\section{IMPACTOS AMBIENTAIS CAUSADOS PELA DEFICIÊNCIA NO SANEAMENTO}

A poluição do meio ambiente é assunto de interesse público em todas as partes do mundo. Não apenas os países desenvolvidos vêm sendo afetados pelos problemas ambientais, como também os países em desenvolvimento. Isso decorre de um rápido crescimento econômico associado à exploração de recursos naturais. Questões como: a escassez e poluição das águas; a baixa qualidade de moradia e ausência de saneamento básico e destinação dos resíduos são de suma importância para a humanidade (BRASIL, 2004).

Em geral, a atividade humana gera impactos ambientais que repercutem nos meios físicos, biológicos e socioeconômicos afetando os recursos naturais e a saúde humana. Esses impactos se fazem sentir nas águas, ar e solo e na própria atividade humana. $O$ conjunto de serviços que compreendem o saneamento básico quando prestados de forma inadequada também causam inúmeros impactos para o meio ambiente.

O impacto ambiental é definido como qualquer alteração no meio ou em algum de seus componentes por determinada ação ou atividade, que afetem a saúde, a qualidade do ambiente e as atividades econômicas e sociais. A Resolução CONAMA n. 001/1986 preconiza que:

Art. $1^{\circ}$ - [...] impacto ambiental qualquer alteração das propriedades físicas, químicas e biológicas do meio ambiente, causada por qualquer forma de matéria ou energia resultante das atividades humanas que, direta ou indiretamente, afetam:

I - a saúde, a segurança e o bem-estar da população;

II - as atividades sociais e econômicas;

III - a biota;

IV - as condições estéticas e sanitárias do meio ambiente;

V - a qualidade dos recursos ambientais (BRASIL, 1986, art. $1^{\circ}$, p. 1 ).

Apesar de antigo o conceito de impacto ambiental e das inúmeras discussões já realizadas acerca da inter-relação entre saneamento, saúde e meio ambiente, ainda é 
comum na atualidade, mesmo com o marcante avanço tecnológico, uma notável ausência do planejamento e de valoração ambiental e de qualidade de vida voltado para a infraestrutura e serviços direcionados para o setor de saneamento (AYACH et al., 2012).

Colaborando assim para a difusão de inúmeros impactos ao meio ambiente, que por muitas vezes tem consequência direta sob a saúde do homem. Entre os problemas decorrentes da falta de saneamento ambiental destacam-se: (I) a contaminação de corpos d'água pelo lançamento de esgoto sanitário e lixos domésticos e industriais; (II) a contaminação do lençol freático, quando é inadequada a localização dos aterros sanitários e há falta de tratamento de esgotos; (III) o assoreamento e a redução do fluxo de escoamento nos canais de drenagem, resultantes da disposição inadequada de resíduos em terrenos baldios e nas margens dos cursos d'água (BRASIL, 2013).

\section{METODOLOGIA}

O presente trabalho foi desenvolvido nos municípios de São Luís, São José de Ribamar, Raposa e Paço do Lumiar, localizados no estado do Maranhão, estes compõem a Região Metropolitana da Grande São Luís (RMGSL). Trata-se dos maiores municípios da região metropolitana, juntos possuem uma população de 1.421 .946 de habitantes e área total de $1412,113 \mathrm{~km}^{2}$ (IBGE, 2010).

A escolha do local de estudo deu-se pelos seguintes fatores: trata-se de municípios que possuem muitos bairros carentes de serviços sanitários, apesar de serem os maiores municípios da RMGSL; além de constantes críticas em relação ao saneamento básico nestas localidades, abordadas nos meios de comunicação.

A Região Metropolitana da Grande São Luís é composta por 13 municípios maranhenses, entre eles São Luís, São José de Ribamar, Raposa, Paço do Lumiar, Alcântara, Bacabeira, Rosário, Morros, Icatu, Santa Rita, Axixá, Cachoeira Grande e Presidente Juscelino, os limites da RMGSL foi instituído pela Lei Complementar $n^{\circ} 161$, de 03 de dezembro de 2013 (FNEM, 2017), os limites territoriais de cada município é apresentado na Figura 01. 
Figura 1 - Limites territorial da Região Metropolitana

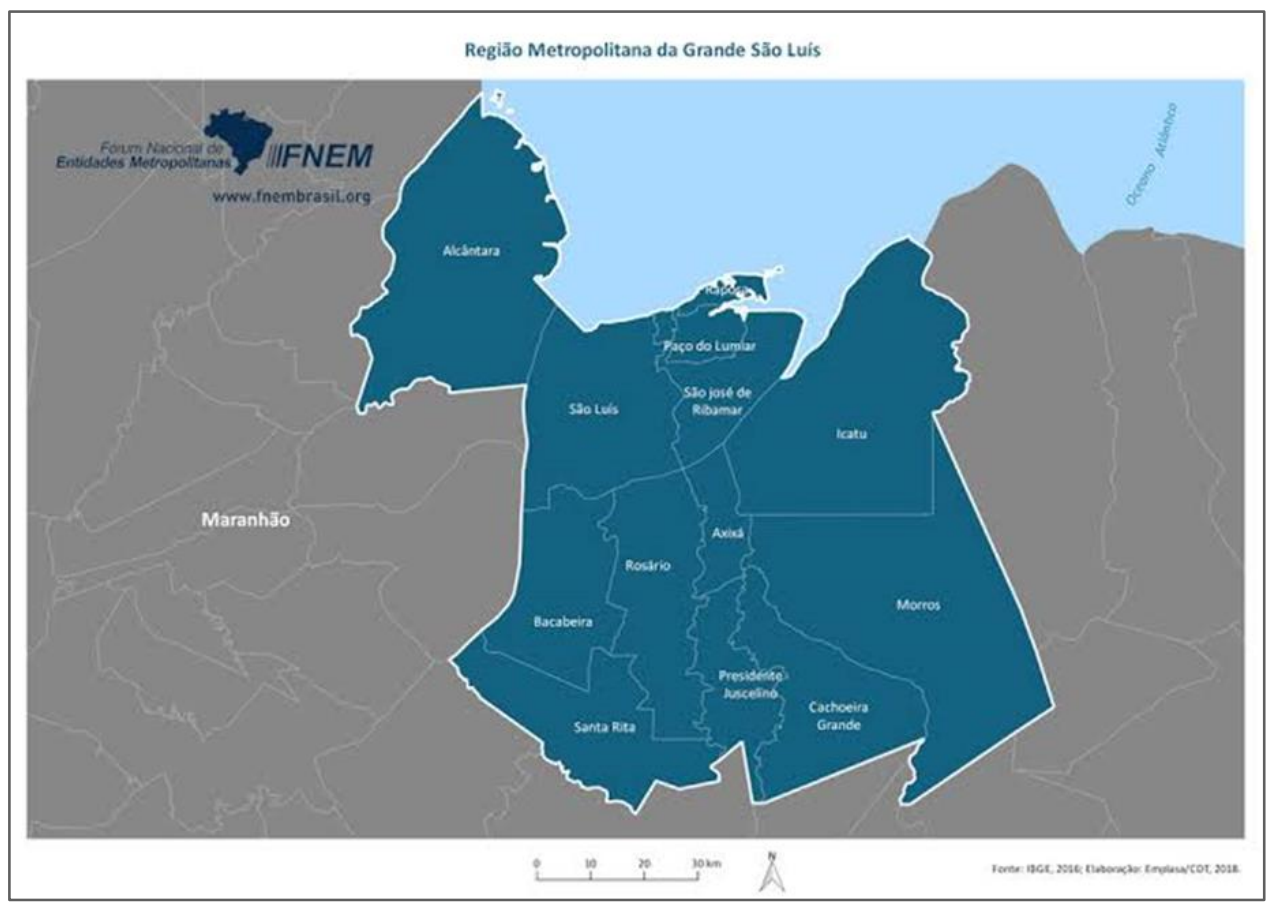

Fonte: FNEM, 2017.

A técnica utilizada para a coleta dos dados foi a aplicação de um questionário estruturado e previamente testado, o questionário continha 12 perguntas acerca dos serviços de saneamento básico desenvolvidos nos municípios de São Luís, São José de Ribamar, Raposa e Paço do Lumiar, o questionário foi criado na ferramenta de formulários disponibilizada pelo Google, Google Formulários, e ficou disponível até serem respondidos 117 questionário, no período de abril e maio de 2019.

A técnica de amostragem da população entrevistada foi executada conforme Gonçalves, Fernandes e Girard (2015) aplicaram em sua pesquisa com objetivo semelhante a esta, que usaram método estatístico, o qual, segundo Oliveira (2004), se leva em consideração o nível de confiança, o erro amostral o qual se pretende admitir e a proporção amostral, bem como o tamanho da população. Seu dimensionamento foi feito para população finita, sendo o valor obtido para a amostra de 117 residências, conforme a Equação 1. 
(1)

$$
n=\frac{Z^{2} \cdot N \cdot(p \cdot q)}{Z^{2}(p \cdot q)+(N-1) \varepsilon^{2}}
$$

Onde:

$Z=$ abscissa da curva normal padrão, fixado nível de confiança de $97 \%=2,17$

$\mathrm{N}=$ tamanho populacional $=1.421 .946$

$\varepsilon=$ erro amostral $=10 \%$

$p \times q=$ proporção amostral $=0,25$.

Para análise dos dados, foram utilizados o Microsoft Excel 2010, onde foram sistematizados e tratados os dados dos questionários e apresentados seus respectivos resultados em forma de gráficos.

\section{RESULTADOS E DISCUSSÕES}

A partir da aplicação dos questionários constatou-se que $80 \%$ dos entrevistados são moradores de São Luís, $12 \%$ de São José de Ribamar, 5\% de Paço do Lumiar e 3\% residentes do município de Raposa.

$\mathrm{Na}$ análise dos dados foi identificado que cobertura do sistema público de abastecimento de água na Região Metropolitana alcança a maioria (82\%) dos imóveis amostrados, como mostra Figura 02. Conforme censo do IBGE, em 2010 71\% dos domicílios da Região Metropolitana da Grande São Luís eram atendidos por rede de água, o que demonstra uma ampliação vegetativa desse serviço na última década. Além disso, $17 \%$ dos entrevistados não são atendidos pelo referido serviço, estes informaram que utilizam outras fontes para abastecimento. 
Figura 2 - Presença do serviço público de abastecimento de água

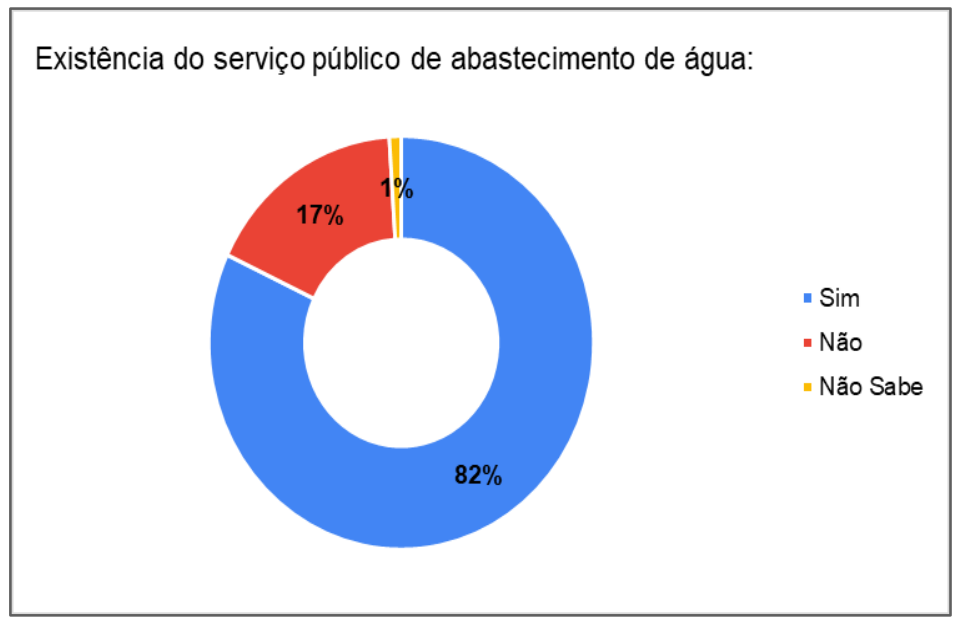

Fonte: Autor, 2019.

Os quatro municípios pesquisados possuem os seus sistemas de abastecimento de água de forma individualizada. No município de São Luís os sistemas de abastecimento de água existentes têm como concessionária a Companhia de Saneamento Ambiental do Maranhão (CAEMA). Já nas sedes municipais de Paço do Lumiar e São Jose de Ribamar, os sistemas de abastecimento de água estão sob a responsabilidade da empresa privada BRK Ambiental. E o município de Raposa o sistema de abastecimento de água está sob a responsabilidade do poder público municipal, por meio do SAAE - autarquia (SNIS, 2018).

No que concerne ao fornecimento de água, foi verificado que em $62 \%$ das residências amostradas não ocorre interrupção no fornecimento de água, enquanto em $38 \%$ falta água periodicamente. A inconsistência no abastecimento de água força os moradores a possuírem alternativas de armazenamento da água, esses locais se não cuidado corretamente pode ser tornar meio de reprodução de insetos transmissores de doenças.

Apesar da maioria dos imóveis amostrados possuírem cobertura do sistema público de abastecimento de água, e, portanto, receberem água tratada em suas residências, boa parte dos entrevistados (71\%) adotam soluções caseiras de tratamento da antes do consumo, tais como filtrar, clorar ou ferver. Com isso, entende-se que a maioria consome água tratada, porém a parcela de pessoas que não tratam a água é bastante significativa 
(29\%), podendo ter efeito direto no acréscimo dos índices de doenças relacionadas a qualidade da água.

Em geral, a implantação do sistema de abastecimento de água, dentro do contexto do saneamento básico é de suma importância para garantir a melhoria da saúde e das condições de vida de uma comunidade (RIBEIRO e ROOKE, 2010).

Em relação ao esgotamento sanitário, averiguou-se que $61 \%$ das residências amostradas tem acesso a rede coletora de esgoto e $31 \%$ não tem acesso, conforme demonstra Figura 03, essa parcela de residências não atendidas por rede coletora de esgoto localiza-se nos municípios de São Luís e São José de Ribamar, conforme pesquisa.

Figura 3 - Existência de rede coletora de esgoto nos imóveis pesquisados

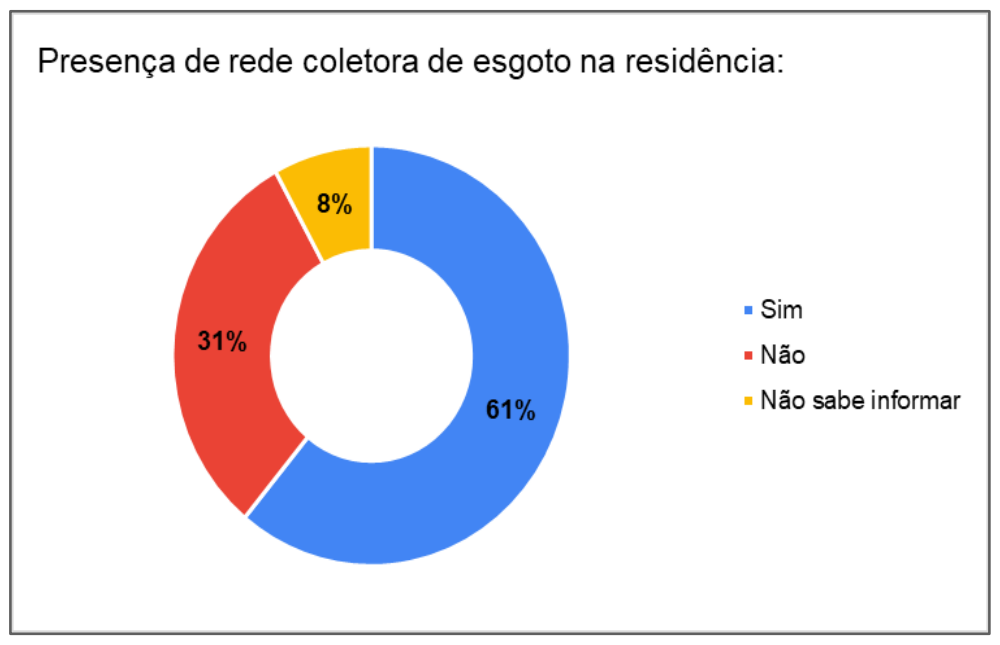

Fonte: Autor, 2019.

Os efluentes domésticos gerados que não são destinados para rede coletora são encaminhados, segundo os moradores, para fossas simples (50\%), fossas sépticas com sumidouro (35\%), para a via pública (14\%) e uma pessoa do município de São Luís, bairro São Bernardo respondeu que destina diretamente para o rio. Ao se destinar efluentes líquidos para fossas simples e/ou a céu aberto (via pública), favorece-se a infiltração do esgoto no solo, com risco constante de contaminação da área e do lençol freático, provocando doenças como a hepatite, cólera e Salmonelose (RIBEIRO e ROOKE, 2010). 
Os serviços públicos de esgotamento sanitário devem ser realizados simultaneamente aos serviços públicos de abastecimento de água. No entanto, os índices de atendimento desse serviço são bastante precários na Região Metropolitana, se comparado ao abastecimento de água. Segundo dados divulgados pela Agência Nacional de Águas (ANA) em 2013, nos municípios estudados da RMGSL em média 58,61\% dos esgotos gerados não possuem coleta e tratamento, 21,58\% são coletados mas não são tratados e 18,86\% são tratados por solução individual e apenas no município de São Luís há tratamento de $3,78 \%$ do esgoto gerado.

Quanto a situação de cada município, tem-se que Paço de Lumiar não trata seu esgoto e direcionam este, quando coletado, para a bacia do rio Santo Antônio (SILVA e VIANA, 2019). Já em Raposa "a solução encontrada pelo município para o esgotamento sanitário na maioria dos domicílios é a individual - isto é, o uso de fossas e sumidouros nos limites de suas propriedades, segundo a Prefeitura Municipal de Raposa" (OLIVEIRA, VIEIRA, CARVALHO, 2014, p. 194).

Em São Luís o sistema de esgotamento sanitário está dividido em 5 bacias de esgotamento sanitário, algumas localizadas em bacias hidrográficas. São bacias de esgotamento sanitário as Bacias: Anil, Bacanga, Paciência, Oceânica e Jeniparana e segundo diversos estudos todas elas sofrem constantemente por descarga de esgoto in natura (SODRÉ e FARIAS FILHO, 2010; OLIVEIRA et al., 2012; SILVA et al., 2014; SILVA, 2015).

Logo, nota-se que os principais problemas de interesse intermunicipal da Região Metropolitana dizem respeito à poluição das bacias hidrográficas, sendo o lançamento de esgotos a principal causa da depreciação da qualidade das águas a jusante de São Luís. É importante ressaltar a descarga de esgoto in natura nos corpos hídricos pode vir a causar uma variedade de impactos negativos, a citar os fenômenos de proliferação de algas (eutrofização) e o consumo de oxigênio no ambiente aquático devido ao processo de estabilização da matéria orgânica, afetando a vida aquática dos organismos aeróbios (VON SPERLING, 2014). 
Sobre a gestão e o gerenciamento dos resíduos sólidos nos municípios pesquisados, constatou-se que em $98 \%$ das residências amostradas tem coleta de resíduo regular, das quais $69 \%$ é realizada 3 vezes na semana. 15\% duas vezes na semana e $14 \%$ é realizada diariamente, de acordo com Figura 04.

\section{Figura 4 - Frequência da coleta de resíduos na RMGSL}

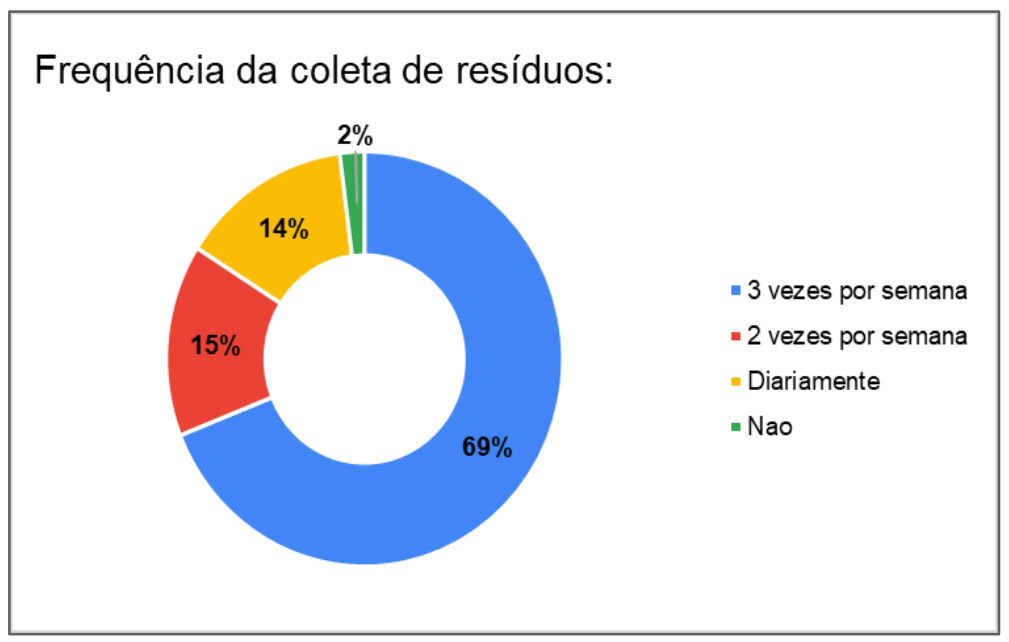

Fonte: Autor, 2019.

Em relação a geração dos resíduos sólidos os municípios de São Luís, São José de Ribamar, Paço do Lumiar e Raposa geram juntos 1.168,99 t/dia, quanto a coleta, há em média um déficit de $10 \%$ do resíduo gerado nesses municípios, sendo mínimo em São José de Ribamar e Paço do Lumiar. Já em São Luís verifica-se déficit diário de coleta de 111,44 t, equivalente a $12 \%$ do resíduo gerado, esse déficit elevado pode comprovar o lançamento inadequado dos resíduos (PGIRS/RMGSL, 2019).

A disposição inadequada dos resíduos sólidos é responsável pela degradação ambiental da paisagem urbana, contaminação e perda dos recursos naturais, além de poder atingir diretamente a saúde do homem (NEPO, 2010). Portanto, o manejo adequado desses materiais é uma importante estratégia de preservação do meio ambiente, assim como de promoção e proteção da saúde do homem (GOUVEIA, 2012).

No que tange à disposição final dos resíduos sólidos todos os municípios pesquisados encaminham seus resíduos para um aterro sanitário privado (CGA Titara), 
contudo, os municípios de Paço do Lumiar e São José de Ribamar apesar de já terem encerrado a disposição de resíduos nos seus lixões, estes ainda continuam necessitando das medidas de recuperação ambiental das áreas degradadas (PGIRS/RMGSL, 2019).

\section{CONCLUSÃO}

Com a metodologia adotada nesta pesquisa foi possível realizar a caracterização da cobertura dos serviços de água, esgoto e resíduos sólidos nos municípios da Região Metropolitana da Grande São Luís, que tratam de forma não integrada sua governança. Foram detectadas, também, lacunas existentes na prestação destes serviços que intensificam os problemas ambientais e de saúde decorrentes do crescimento urbano e má gestão.

Destaca-se os seguintes resultados, $82 \%$ dos imóveis amostrados são atendidos pelo serviço de abastecimento de água, $99 \%$ são atendidos pela coleta de resíduos e $61 \%$ são ligados a rede coletora de esgoto, contudo registra-se a fragilidade no sistema de esgotamento sanitário, uma vez que as redes existentes encaminham os esgotos coletados direto para os corpos hídricos da RMGSL, apenas o município de São Luís trata uma ínfima parte dos esgotos coletados.

Portanto, a metodologia de avaliação do sistema a partir da percepção do usuário, mostrou-se ferramenta importante, que em conjunto com as ações de operação, manutenção e melhorias e expansão dos serviços, são imprescindíveis à gestão e ao planejamento e à credibilidade do sistema, bem como para o monitoramento do mesmo.

\section{REFERÊNCIAS}

ARAÚJO, Bequiane Pereira de Araújo et al.. Saneamento básico: estudo de caso no bairro Morro do Pequi Corrente, PI. In: Congresso Brasileiro de Gestão Ambiental, 7., 2016, Campina Grande/PB. Anais... Campina Grande/PB, 2016.

AYACH, Lucy Ribeiro et al.. Saúde, saneamento e percepção de riscos ambientais urbanos. Caderno de Geografia, Belo Horizonte, v. 22, n. 37, p.47-64, 2012. 
BRASIL. Fundação Nacional de Saúde. Manual do Saneamento. 3 ed. rev. - Brasília: Fundação Nacional de Saúde - FUNASA, 2004. 408 p.

BRASIL. Lei $n^{\circ} 11.445$, de 5 de janeiro de 2007. Estabelece diretrizes nacionais para o saneamento básico; altera as Leis nos 6.766, de 19 de dezembro de 1979, 8.036, de 11 de maio de 1990, 8.666, de 21 de junho de 1993, 8.987, de 13 de fevereiro de 1995; revoga a Lei $n^{\circ} 6.528$, de 11 de maio de 1978; e dá outras providências. Publicado no DOU de 8.1.2007 e retificado no DOU de 11.1.2007.

BRASIL. Fundação Nacional de Saúde. Resíduos sólidos e a saúde da comunidade: informações técnicas sobre a interrelação saúde, meio ambiente e resíduos sólidos. Brasília: Fundação Nacional de Saúde - FUNASA, 2013. 44 p.

GONÇALVES, Keyt Oliveira; FERNANDES, Lindemberg Lima; GIRARD, Luiza. Diagnóstico do serviço de abastecimento de água na percepção do usuário no município de Barcarena - Pará.

Revista Monografias Ambientais - Remoa, Santa Maria, v. 14, n. 1, p.20-25, jan. 2015.

GOUVEIA, Nelson. Resíduos sólidos urbanos: impactos socioambientais e perspectiva de manejo sustentável com inclusão social. Ciência e Saúde Coletiva, São Paulo, v. 6, n. 17, p.15031510, abr. 2012.

OLIVEIRA, Paulo Henrique F. C. Amostragem básica - Aplicação em auditoria. Ed. Ciência Moderna Ltda, 2004.

OLIVEIRA, Dulce Raquel Pereira Oliveira et al.. Avaliação do grau de contaminação microbiológica do estuário do Rio Paciência, Estado do Maranhão. Arquivos de Ciências do Mar, Fortaleza, v. 45, n. 1, p. 56-61, 2012.

OLIVEIRA, Mayara Silva. VIEIRA, Andressa Brito, CARVALHO, Mônica Teixeira. Saneamento ambiental na Grande São Luís: o que os olhos não veem, a população sente. Instituto de Pesquisa Econômica Aplicada - ipea 2014. Funções públicas de interesse comum nas metrópoles brasileiras: transportes, saneamento básico e uso do solo / organizadores: Marco Aurélio Costa, Bárbara Oliveira Marguti. - Brasília: IPEA, 2014. p. 187-209.

RIBEIRO, Júlia Werneck; ROOKE, Juliana Maria Scoralick. Saneamento básico e sua relação com o meio ambiente e a saúde pública. 2010. 36 f. TCC (Especialização) - Curso de Especialização em Análise Ambiental, Universidade Federal de Juiz de Fora, Juiz de Fora, 2010.

SILVA, Isadora de Queiroz da. Análise preliminar dos sistemas de abastecimento de água e esgotamento sanitário em São Luís do Maranhão, Brasil: um enfoque ambiental. 2015. 71 f. TCC (Graduação) - Curso de Ciência e Tecnologia - BICT, Universidade Federal do Maranhão, Maranhão, 2018. 
SILVA, Gilmar Silvério da et al.. Avaliação integrada da qualidade de águas superficiais: grau de trofia e proteção da vida aquática nos rios Anil e Bacanga, São Luís (MA). Engenharia Sanitária e Ambiental, Rio de Janeiro, vol.19, n.3, jul./set. 2014.

SILVA, Isael Gomes; VIANA, Michael Barbosa Viana. Implantação de sistema de esgotamento sanitário no bairro Vila Epitácio Cafeteira - trecho da Bacia do rio Santo Antônio - no município de Paço do LUMIAR/MA. Revista Caribeña de Ciencias Sociales, Málaga, Espanha, v., n., jul. 2019.

SIQUEIRA, Mariana Santiago et al.. Internações por doenças relacionadas ao saneamento ambiental inadequado na rede pública de saúde da região metropolitana de Porto Alegre, Rio Grande do Sul, 2010-2014. Epidemiologia e Serviços de Saúde, Brasília, 26(4):795-806, outdez 2017.

SNIS. Sistema Nacional de Informações sobre Saneamento. Diagnóstico de Água e Esgoto 2018 - série histórica - municípios: São Luís, São José de Ribamar, Paço do Lumiar e Raposa. Brasília, 2018.

VON SPERLING, M. Introdução à qualidade das águas e ao tratamento de esgotos. Princípios do tratamento biológico de águas residuárias. 4ª Edição. Volume 1. Editora UFMG. Belo Horizonte, 2014. 